\title{
Maternal Health Status and Parenting Stress in Low-Income, Ethnic-Minority Mothers of Children with Conduct Disorder Problems: the Role of Daily Parenting Hassles
}

\author{
Rhonda BeLue $^{1} \cdot$ Linda C. Halgunseth $^{2} \cdot$ Beatrice Abiero $^{1} \cdot$ Phylicia Bediako $^{1}$
}

Received: 29 September 2014 / Revised: 23 January 2015 / Accepted: 27 February 2015 /Published online: 20 March 2015

(C) W. Montague Cobb-NMA Health Institute 2015

\begin{abstract}
Objectives Minimal attention has been given to understanding parenting stress among low-income, ethnically diverse mothers of children with conduct problems. Maternal health and parenting hassles may serve as important risk factors for parenting stress. This study examined whether parenting hassles mediated the relations between maternal physical and mental health and parenting stress in a sample of low-income, ethnically diverse mothers of children with behavioral problems.

Methods The sample included 177 low-income black, Latina, and white mothers of kindergartners with behavior problems. Path analysis was employed to assess the associations between maternal mental and physical health and parenting stress, as well as the moderating role of parenting hassles in this cross-sectional study.

Results After adjusting for covariates, we found that parenting hassles mediated the relationship between social support and parenting stress as well as maternal health and parenting stress.

Conclusion Findings suggest that promoting coping resources for daily parenting hassles and supporting the physical and mental health of minority mothers may have important implications for parenting children with high behavior problems.
\end{abstract}

Keywords Parenting stress $\cdot$ Maternal health $\cdot$ Parenting hassles

Rhonda BeLue

rzb10@psu.edu

1 The Pennsylvania State University, University Park, PA, USA

2 University of Connecticut, Waterbury, CT, USA

\section{Introduction}

Parenting stress is defined as feelings of anxiety that arise when the demands of the childrearing process are perceived as greater than personal and social resources [1,2]. While the process of parenting can be stressful for many parents, research suggests that ethnic-minority parents who are of lower socioeconomic status (SES) and who care for children with behavior problems are particularly vulnerable to feelings of parenting stress [3-6]. Minimal research has examined protective and risk factors associated with parenting stress in this vulnerable population of parents. Belsky's [7] ecological framework on parenting suggests that the joint effects of maternal health (physical and mental), the ability to manage daily hassles, and levels of social support may explain variability in parenting stress.

\section{Parenting Stress}

Parenting stress has been linked to harsh parenting, maternal depression, and poor cognitive, socioemotional, and physical development in children [8-14]. Parenting stress is thought to more directly affect parenting practices and family dynamics more so than other sources of stress such as workplace or financial stress. Parenting stress may have long lasting effects on the well-being of parents and children given the ongoing and intimate nature of parenting stress and its impact on the entire family [8].

Belsky's [7] ecological framework on parenting explains how parenting stress is linked to poor parent, child, and family functioning. According to this interactive model, parenting is influenced by three areas: (a) personal resources of parent, (b) contextual sources of stress and support, and (c) characteristics of the child. Problems in these three areas are associated 
with poor parental functioning, which in turn is linked to poor child and family outcomes. In support of this model, past research has found that maternal depression, difficult child temperament, child behavior problems, low social support, and limited financial resources are linked to high levels of parenting stress and harsh parenting practices $[2-6,8,12$, 15]. Relatively less research has examined how maternal physical health influences parenting stress, especially in contexts where mothers are struggling to raise high-risk children with limited financial and social resources. The management of parenting stress may play an important role in the wellbeing of low-income and minority mothers and children across multiple stages of child development.

\section{Maternal Physical and Mental Health}

Mothers with poor physical health may experience additional obstacles in parenting, such as rapid cognitive and physical fatigue, which may lead to high levels of parenting stress and poor child outcomes [16]. White et al. [17] examined a sample of mothers who were diagnosed with multiple sclerosis (MS) and rheumatoid arthritis. Their findings revealed that for RA mothers, fatigue was a significant predictor of parenting stress, while for mothers with MS, the number of children in their families and their sleep quality and quantity were associated with high levels of parenting stress. In a related study, Poole et al. [18] examined a sample of mothers who were diagnosed with scleroderma. Mothers in this sample reported that their health interfered with certain aspects of motherhood such as being able to get up and down from the floor to play with their children.

Maternal mental health has also been found to predict higher levels of parenting stress $[10,12,19]$ and poor child outcomes $[16,20]$. Mothers who suffer from depression may have difficulty attending to their children's basic needs and providing the necessary physical comfort and emotional sensitivity necessary for positive child well-being [11]. Using a national sample, Mistry et al. [9] found that mothers who reported poor mental health were more likely than their healthy counterparts to report parenting stress such as not being able to afford child care and receiving insufficient emotional and functional support in parenting 4-to-35month-old children [9].

\section{Socioeconomic Status and Social Support}

Mothers of low-socioeconomic status (SES) and who are ethnically or racially diverse are particularly vulnerable to poor physical and mental health [21-23] and high parenting stress [4-6]. This may be due to structural disadvantages such as limited access to quality health care and low social and financial support $[2,4,10]$. Using national datasets, Nomaguchi and colleagues have found parenting stress to be higher among less educated than more educated mothers and among black mothers versus white mothers of kindergartners $[4,5]$. Past research has also found that inadequate social support and health-related inactivity were stronger predictors of parenting stress than maternal race/ethnicity, age, or education $[2,10]$. Lastly, a study found disproportionately higher levels of parenting stress and higher rates of poor maternal mental health among the lower income families in their sample [9]. Thus, low-income mothers may be particularly vulnerable to poor health, which may introduce additional obstacles to the parenting process; these obstacles, in turn, may exacerbate levels of stress that arise when performing dayto-day parenting activities $[4,17,22]$.

\section{Parenting Hassles}

Parenting hassles refer to the day-to-day parenting tasks that over time may cumulatively cause irritation, frustration, stress, or annoyance in parents [6]. Parenting hassles differ from parenting stress in that the former focuses on stress that results from performing everyday parenting activities (e.g., household tasks) whereas parenting stress refers to feelings of distress that stem from poor parental self-competence and dysfunctional parent-child relationships [24, 25]. Belsky's [7] parenting model posits that poor parental resources, difficult child characteristics, and low levels of financial and social support may influence parents' ability to cope with daily parenting hassles which, in turn, lead to higher levels of parenting stress and lower parent functioning. To our knowledge, no study has examined whether parenting hassles serve as risk or protective factor among low-income ethnically diverse mothers who are simultaneously raising children with conduct problems and coping with their own poor physical and mental health conditions.

\section{Study Goals and Hypotheses}

All study goals and hypotheses were guided by Belsky's [7] ecological theory of parenting, which suggests that healthy parental functioning is influenced by parents' personal resources, social support, and child characteristics. Using a sample of low-income, ethnically diverse mothers of children with conduct problems, we examined the relations between social support, parenting hassles, maternal health status, and perceived stress while taking into account sociodemographic factors: specifically, we examined whether poor maternal health was associated with greater parenting hassles, which in turn, would be related to greater parenting stress among lowincome minority mothers, and whether social support buffered 
the effect of hassles and health on parenting stress. We hypothesized that (1) the relationship between parenting hassles and stress would be stronger as maternal health worsened, and (2) mothers who reported greater social support would experience fewer parenting hassles and parenting stress regardless of health status.

\section{Methods}

\section{Sample}

The current study examined home-interview data from 177 mothers who reported that they were the head of the household and whose children were participating in a larger study titled Paths-to-Success [26]. While some families in Paths-toSuccess later received intervention services, all data examined in this study were collected at baseline visits before those services began. Families were recruited from schools located within an economically disadvantaged Northeastern city, in which $86 \%$ of children in the schools qualified for free and reduced lunch. On average, mothers were 29.3 years old $(\mathrm{SD}=6.3)$ at the time of the interview. Sixteen percent of mothers reported that they spoke both English and Spanish in the home. Only two mothers reported exclusively speaking Spanish. The majority of the mothers reported that they were either the only parent $(67 \%)$ or the primary caregiver (see Table 1 for demographic characteristics). Informed consent was obtained from all individual participants included in the study. This study was approved by the Institutional Review Board at the lead author's institution.

\section{Procedure}

Baseline assessments were collected in the fall of kindergarten. Teachers rated children at school on areas of child behavior using the Teacher Observation of Child Adaptation-Revised (TOCA-R) [27]. Families whose children represented the top quintile of behavior problems on the TOCAauthority acceptance subscale were invited to participate in home interviews. Trained interviewers went to homes of participants and administered interviews upon obtaining consent. Interviewers read all questions to parents and recorded their answers to avoid concerns about low levels of literacy. Mothers were asked about their health, approach to childrearing, family circumstances, and the kinds of behavior their children displayed at home. Mothers were reimbursed $\$ 75.00$ for their time.

\section{Measures}

Physical Health Status Mothers self-reported on their general health. Scores ranged from 1 to 5: 1=excellent, $2=$ very
Table 1 Means, standard deviations, and percentages of demographic variables $(N=117)$

\begin{tabular}{|c|c|c|c|}
\hline Variable & & $M(\mathrm{SD})$ & Percent \\
\hline Mother's age & & $29.8(6.3)$ & \\
\hline Physical health & & $3.5(1.2)$ & \\
\hline Mental health & & $15.2(11.2)$ & \\
\hline \multicolumn{4}{|c|}{ Currently employed? } \\
\hline & $\%$ Yes & & 49.0 \\
\hline \multicolumn{4}{|c|}{ Educational level } \\
\hline & $\%$ Less than high school & & 24.9 \\
\hline & \% Completed high school & & 36.1 \\
\hline & $\%$ Greater than high school & & 39.0 \\
\hline \multicolumn{4}{|l|}{ Marital status } \\
\hline & $\%$ Married & & 12.5 \\
\hline & $\%$ Single & & 67.6 \\
\hline & $\begin{array}{l}\text { \% Living with a romantic } \\
\text { partner }\end{array}$ & & 19.9 \\
\hline \multicolumn{4}{|l|}{ Race of mother } \\
\hline & $\%$ Black & & 70.7 \\
\hline & $\%$ White & & 22.6 \\
\hline & $\%$ Latina & & 6.7 \\
\hline \multicolumn{4}{|l|}{ Gender } \\
\hline & $\%$ Female & & 32.2 \\
\hline & $\%$ Male & & 67.8 \\
\hline
\end{tabular}

good, $3=$ good, $4=$ fair, and 5=poor. Mothers reporting fair or poor health were considered to have poor physical health.

Mental Health Status Depression was measured using the 20 -item Center for Epidemiologic Studies Depression Scale (CESD) [28]. Sample items included "During the past week, how often were you bothered by things that don't usually bother you?" and "How often did you feel sad?" Individual items were rated on a four-point Likert scale with response options ranging from $0=$ rarely to $3=$ almost all the time. A mean score was calculated $(M=15.2, \mathrm{SE}=11.2$, range $0-53)$. Cronbach's alpha was 0.79 . A higher score indicated more severe depression. Participants with a score of 16 or greater, the recommended clinical cutoff for the scale, were categorized as having poor mental health.

Parenting Stress Mothers self-reported on their level of parenting stress using the Parenting Stress Index (PSI) [1]. This index measured perceptions of stress related to parenting activities. Mothers were asked about the frequency in which they agreed to the following questions: "When I do things for my child, I get the feeling that my efforts are not appreciated very much"; "My child doesn't seem to smile as much as most children"; "I expected to have closer and warmer feelings for my child than I do, and this bothers me"; "My child generally wakes up in a bad mood"; "I feel that my child is 
very moody and easily upset"; "My child makes more demands on me than most children"; "My child rarely does things for me that make me feel good." From the current data, a mean score was calculated $(M=1.9, \mathrm{SE}=0.7$, range $1-4$.). Cronbach's alpha was 0.84 . A higher score indicated higher parenting stress.

Parenting Daily Hassles Parenting hassles were assessed as feelings of irritation that arise from everyday activities [24]. Participants rated a total of 12 hectic parenting events, including (1) mealtime difficulties, such as picky eaters and complaining; (2) trouble finding someone to take care of your child when you need to do something else; (3) the children's schedules interfere with what you need to do at home; (4) the children argue and fight; (5) children resist bedtime; (6) children constantly get in the way or interfere with chores; (7) you have to change your plans because your child needs something unexpectedly; (8) children get dirty several times a day, requiring many changes of clothes; (9) trouble getting children ready for school or leaving on time; and (10) difficulties in finding good childcare for your children. Participant responses ranged from $1=$ rarely to $4=$ almost always. A mean score was calculated $(M=2.0, \mathrm{SE}=0.5$, range 1-3.5). Cronbach's alpha was 0.72 . Higher scores indicated higher parenting hassles.

Social Support Participants indicated their levels of satisfaction with social support [24]. On a scale from 1 to 4 , mothers rated their level of satisfaction to the following questions:"How satisfied are you with availability if family and friends to talk to whose advice you trust?", "How satisfied are you with the amount of phone contact you have with friends?", "How satisfied are you with the availability of someone to share with when you are feeling happy or feeling good?", "How satisfied are you with the availability of someone to share with when you are feeling upset or angry?", "How satisfied are you with the amount of contact you have with your parents?", "How satisfied are you with the amount of contact you have with your in-laws or other relatives?", "How satisfied are you with the amount of help that family members provide?", "How satisfied are you with the availability of someone to share your most personal feelings with?" From the current data a mean score was calculated $(M=3.1$, $\mathrm{SE}=0.6$, range 1-4). Cronbach's alpha was 0.85. Higher scores indicated greater levels of social support.

Sociodemographic Measures Mothers reported on several sociodemographic indicators such as their age in years, child race (e.g., black, Latina, white), child sex (e.g., male vs female), maternal employment status (e.g., working outside of the home or not), maternal education level (less than high school, high school only, greater than high school), and marital status (e.g., married, single, living with a romantic partner).

\section{Results}

\section{Analytic Approach}

Means, standard deviations, and frequencies were calculated for demographic and all study variables (see Table 1). $t$ Tests were calculated to examine whether maternal physical and mental health (good or poor) were associated with maternal parenting stress and children's behavioral outcomes. $t$ Tests and chi-squared tests were also used to examine whether maternal physical and mental health were related to demographic variables (see Table 2). Analysis of variance (ANOVA), $t$ tests, and correlations were calculated to examine whether levels of parenting stress differed across demographic variables (see Tables 2, 3 and 4).

Lastly, path analysis was used to examine the relationship between maternal health status, social support, parenting hassles, and parenting stress. Path analysis was used to estimate the effect of independent variables on parenting stress, our outcome of interest, while controlling for other variables of interest (e.g., age).

After standardizing all continuous variables, we began the path analysis by developing a moderation model to represent our hypotheses. The physical and mental health variables were operationalized as a single latent variable called health.

Using multiple regression analysis, we estimated the path coefficients to identify significant and nonsignificant paths between variables. The path coefficients represented the direct effects of each variable controlling for all other variables (see Fig. 2). Indirect effects were calculated using the distribution of the product of the coefficients method [27].

\section{Descriptive Analyses}

Mothers reported that their children were mostly black (66\%), followed by Latina (21\%), white (7\%), and other (6\% Asian or mixed race). On average, there were three $(\mathrm{SD}=0.13)$ children per household. All children were in kindergarten at the time of the mother's interview. Participating mothers were on average 29.8 years old $(\mathrm{SD}=6.3)$. About $25 \%$ of the sample had not completed high school, and only $39 \%$ reported an educational level beyond high school. The majority of mothers were single $(67.6 \%)$; however, $12.5 \%$ reported being married, and $19.9 \%$ reported living with a romantic partner. Slightly over half $(51 \%)$ of the mothers reported that they were not working outside of the home (see Table 1).

Forty percent of mothers reported a score of over 16 on the CESD, indicative of poor mental health (CESD; $M=15.2$, $\mathrm{SD}=11.2$ ). Approximately $24 \%$ of the sample reported that they were in fair or poor physical health $(M=3.5, \mathrm{SD}=1.2)$. There were twice as many boys as girls in the sample (68 vs $32 \%$; see Table 1). 
Table 2 Analysis of variance (ANOVA), $t$ tests, and correlation results comparing study variables across sociodemographic variables $(N=177)$

\begin{tabular}{|c|c|c|c|c|c|}
\hline Variables $M(\mathrm{SD})$ & & $\begin{array}{l}\text { Parenting } \\
\text { stress } 1.9(0.7)\end{array}$ & $\begin{array}{l}\text { Parenting } \\
\text { hassles } 2.0(0.5)\end{array}$ & $\begin{array}{l}\text { Physical } \\
\text { health } 0.5(1.2)\end{array}$ & $\begin{array}{l}\text { Mental } \\
\text { health } 15.2(11.2)\end{array}$ \\
\hline Age $(r)$ & & 0.01 & $0.45^{\wedge \wedge \wedge}$ & -0.07 & 0.12 \\
\hline \multicolumn{6}{|c|}{ Currently employed? } \\
\hline \multicolumn{6}{|l|}{ Yes } \\
\hline \multicolumn{6}{|l|}{ No } \\
\hline \multicolumn{6}{|l|}{$M(\mathrm{SD})$} \\
\hline & Yes & $2.0(0.7)$ & $2.1(0.5)^{* *}$ & $3.4(1.2)$ & $13.7(11.8)^{*}$ \\
\hline & No & $1.8(0.7)$ & $1.8(0.7)$ & $3.6(1.1)$ & $16.8(10.3)$ \\
\hline \multicolumn{6}{|l|}{ Education level } \\
\hline \multicolumn{6}{|l|}{$M(\mathrm{SD})$} \\
\hline & Less than high school & $2.3(0.8)++$ & $2.1(0.4)++$ & $3.4(1.2)+$ & $19.5(13.3)+$ \\
\hline & Completed high school & $1.9(0.6)$ & $1.9(0.5)$ & $3.9(0.9)$ & $13.8(9.9)$ \\
\hline & Greater than high school & $1.7(0.6)$ & $1.9(0.4)$ & $3.2(1.2)$ & $13.6(10.3)$ \\
\hline \multicolumn{6}{|l|}{ Marital status } \\
\hline \multicolumn{6}{|l|}{$M(\mathrm{SD})$} \\
\hline & Married & $1.7(0.5)$ & $2.0(0.5)$ & $3.5(1.4)$ & $15.9(12.6)$ \\
\hline & Single & $1.7(0.7)$ & $1.9(0.5)$ & $3.5(1.2)$ & $15.7(11.2)$ \\
\hline & Living with a romantic partner & $1.9(0.8)$ & $2.0(0.4)$ & $3.6(1.0)$ & $13.1(10.3)$ \\
\hline \multicolumn{6}{|l|}{ Race of mother } \\
\hline \multicolumn{6}{|l|}{$M(\mathrm{SD})$} \\
\hline & Black & $1.8(0.6)++$ & $1.9(0.5)$ & $3.6(1.1)$ & $13.7(9.7)+$ \\
\hline & White & $2.3(0.9)$ & $1.9(0.5)$ & $3.3(1.3)$ & $16.2(15.7)$ \\
\hline & Latina & $1.9(0.8)$ & $1.9(0.5)$ & $3.4(1.3)$ & $18.4(11.8)$ \\
\hline Social support & & $-0.071^{\wedge}$ & -0.12 & $0.23^{\wedge}$ & $0.34^{\wedge \wedge \wedge}$ \\
\hline $3.2(0.6)$ & & & & & \\
\hline
\end{tabular}

ANOVA results: $+p<0.05,++p<0.001,+++p<0.0001 ; t$ test results: ${ }^{*} p<0.05,{ }^{*} p p<0.001,{ }^{* * *} p<0.0001$; correlation results: ${ }^{\wedge} p<0.05, \wedge \wedge p<0.001$, $\wedge \wedge p<0.0001$

\section{Bivariate Analyses}

Older mothers reported more parenting hassles compared to younger mothers. Mothers who worked reported better mental health but higher parenting stress compared to nonworking mothers. Similarly, mothers who had less than a high school education experienced more parenting hassles and stress compared to mothers with more education. Black mothers reported

Table 3 Correlation matrix with significant correlations bolded

\begin{tabular}{|c|c|c|c|c|c|c|c|c|c|c|}
\hline & Age & Work & White & Latina & Black & Physical & Mental & Support & Hassles & Stress \\
\hline Age & 1.000 & & & & & & & & & \\
\hline Work & 0.057 & 1.000 & & & & & & & & \\
\hline White & -0.121 & -0.028 & & & & & & & & \\
\hline Latina & -0.088 & -0.031 & & & & & & & & \\
\hline Black & $0.160^{*}$ & 0.043 & & & & & & & & \\
\hline Physical & 0.071 & -0.103 & 0.069 & 0.069 & -0.102 & 1.000 & & & & \\
\hline Mental & 0.123 & $-0.150^{*}$ & 0.133 & 0.037 & -0.142 & $0.451^{* *}$ & 1.000 & & & \\
\hline Support & -0.032 & -0.012 & -0.142 & -0.074 & $0.171^{*}$ & $-0.227 * *$ & -0.061 & 1.000 & & \\
\hline Hassles & -0.071 & $-0.203^{* *}$ & 0.087 & -0.044 & -0.055 & $0.234^{* *}$ & $0.451^{* *}$ & $-0.223^{* *}$ & 1.000 & \\
\hline Stress & -0.089 & -0.114 & $0.281 * *$ & 0.021 & $-0.269 * *$ & $0.172 *$ & $0.381 * *$ & -0.119 & $0.414 * *$ & 1.000 \\
\hline
\end{tabular}

$* p<0.05, * * p<0.001$ 
Table 4 Results of path analysis

\begin{tabular}{|c|c|c|c|c|}
\hline & Estimate & Standard deviation & Est./SE & $p$ value \\
\hline \multicolumn{5}{|l|}{ Stress on } \\
\hline Health & -0.069 & 0.080 & -0.865 & 0.387 \\
\hline Hassles & 0.372 & 0.071 & 5.254 & 0.000 \\
\hline Support & -0.116 & 0.116 & -1.004 & 0.316 \\
\hline Age & -0.004 & 0.011 & -0.334 & 0.738 \\
\hline Marital & 0.162 & 0.122 & 1.332 & 0.183 \\
\hline Black & -0.551 & 0.165 & -3.334 & 0.001 \\
\hline Latina & -0.298 & 0.303 & -0.985 & 0.325 \\
\hline Education & -0.313 & 0.090 & -3.481 & 0.001 \\
\hline Work & 0.020 & 0.139 & 0.144 & 0.886 \\
\hline \multicolumn{5}{|l|}{ Health on } \\
\hline Age & 0.006 & 0.007 & 0.964 & 0.335 \\
\hline Marital & -0.051 & 0.074 & -0.689 & 0.491 \\
\hline Black & -0.092 & 0.101 & -0.910 & 0.363 \\
\hline Latina & -0.034 & 0.181 & -0.186 & 0.853 \\
\hline Education & -0.161 & 0.054 & -2.981 & 0.003 \\
\hline Work & -0.040 & 0.084 & -0.473 & 0.636 \\
\hline \multicolumn{5}{|l|}{ Support on } \\
\hline Age & -0.018 & 0.008 & -2.420 & 0.016 \\
\hline Marital & 0.087 & 0.086 & 1.018 & 0.309 \\
\hline Black & 0.130 & 0.117 & 1.116 & 0.264 \\
\hline Latina & -0.378 & 0.211 & -1.787 & 0.074 \\
\hline Education & -0.029 & 0.063 & -0.456 & 0.649 \\
\hline Work & 0.156 & 0.097 & 1.616 & 0.106 \\
\hline \multicolumn{5}{|l|}{ Hassles on } \\
\hline Age & -0.007 & 0.012 & -0.568 & 0.570 \\
\hline Marital & 0.002 & 0.141 & 0.015 & 0.988 \\
\hline Black & -0.127 & 0.191 & -0.668 & 0.504 \\
\hline Latina & -0.282 & 0.346 & -0.814 & 0.416 \\
\hline Education & -0.111 & 0.103 & -1.077 & 0.281 \\
\hline Work & -0.393 & 0.158 & -2.488 & 0.013 \\
\hline Hassles with health & 0.139 & 0.045 & 3.068 & 0.002 \\
\hline Hassles with support & -0.153 & 0.048 & -3.187 & 0.001 \\
\hline Health with support & -0.076 & 0.027 & -2.873 & 0.004 \\
\hline
\end{tabular}

lower levels of parenting stress and depression compared to Latina and white mothers (see Tables 2 and 3). Notably, parenting stress was positively related to poor physical health, and mental health increased parenting hassles but was not significantly correlated to social support. However, parenting hassles were negatively correlated with social support, implying that mothers with more social support experienced fewer parenting hassles (Table 3). The association between social support and race was marginally significant $(p=0.067)$; the trend suggests that white mothers reported less social support $(M=2.7)$ than blacks $(M=3.1)$ and Latinas $(M=3.2)$. Child gender was not related to any of our variables of interest.

\section{Path Analyses}

Figure 1 displays the proposed path model. Figure 2 displays the tested path model with only significant paths shown. Table 4 presents all path coefficients, standard errors, and levels of significance.

\section{Parenting Stress}

Only education $(-0.313(0.09))$ and black race $(-0.551$ $(0.165))$ are directly related to parenting stress meaning that compared to mothers with lower education, more educated mothers experienced less parenting stress. Compared to white and Latina mothers, black mothers experience less parenting stress. Only education was directly related to maternal health, with more educated mothers having better health status $(-0.161(0.054))$. Work status was indirectly related to parenting stress through parenting hassles.

\section{Parenting Hassles}

Mothers who work outside of the home directly experienced fewer parenting hassles $(-0.393(0.153))$. Increased support was related to fewer parenting hassles $(-0.153(0.048))$, and poorer health status was related to increased hassles $(0.139$ $(0.045))$. As hassles increase, parenting stress increases $(0$. $372(0.071))$.

\section{Social Support}

Older mothers have slightly less social support, and as social support increased, mothers were less likely to have poor health $(-0.076(0.027))$. There is no direct effect between social support and parenting stress. Social support is related to $(-0.153$ $(0.048))$ parenting stress through parenting hassles $(0.372$ (0.071)).

\section{Support, Stress, Hassles, and Health}

In partial support of our first hypothesis, while health was not directly related to parenting stress, it was indirectly related through parenting hassles with a total indirect effect 0.052 $(\mathrm{SE}=0.02 ; 95 \% \mathrm{CI}$ is $[0.017,0.094])$.

In partial support of our second hypothesis, while support was not directly related to parenting stress, it was indirectly related through parenting hassles with an indirect effect of -0.057 ( $\mathrm{SE}=0.021 ; 95 \% \mathrm{CI}$ is $[-0.103,-0.02])$. Work status was also indirectly related to parenting stress through hassles with an indirect effect of -0.146 ( $\mathrm{SE}=0.066 ; 95 \% \mathrm{CI}$ $[-0.288,-0.029])$. 
Fig. 1 Path models to be tested. Note: race is specified as binary indicator variables

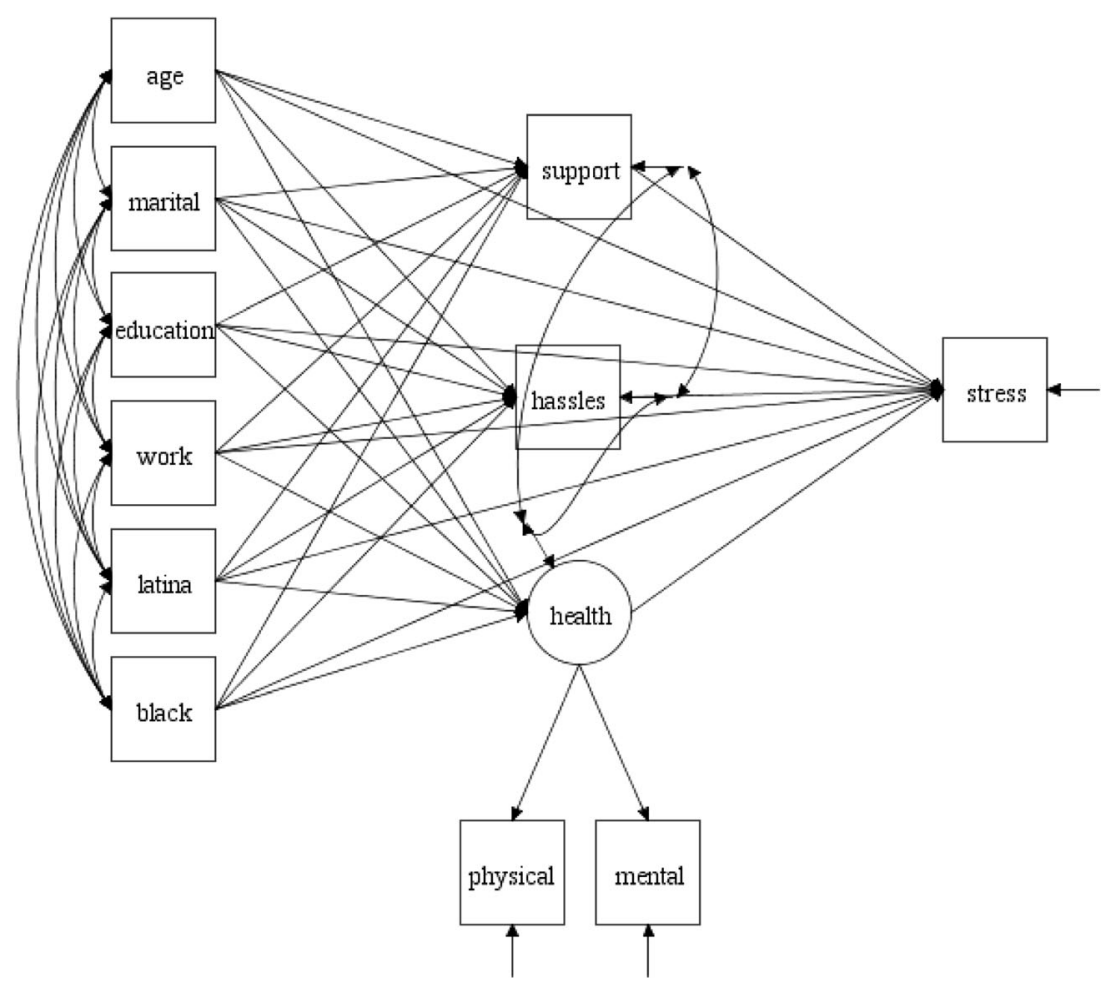

\section{Discussion}

This study examined a unique population that has received limited attention in the empirical literature on parenting stress - low-income, ethnically diverse mothers of schoolaged children with early conduct problems. Considering the impact parenting stress has on parenting and child development, it is critical that practitioners and prevention scientists
Fig. 2 Path results: only significant paths are shown: path coefficient (SE)

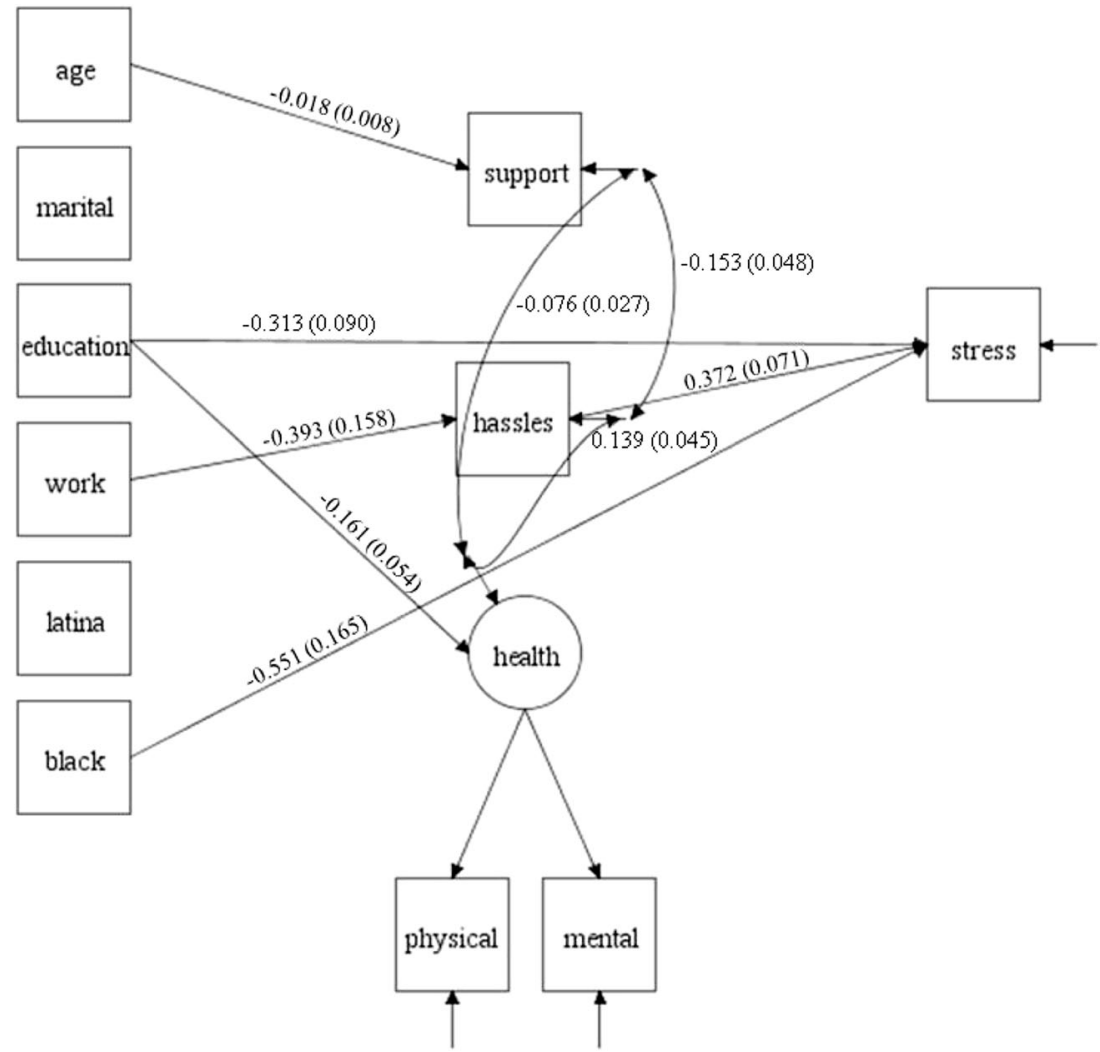


are informed on important risk and protective factors associated with parenting stress in this vulnerable population. To our knowledge, this study was the first to examine the interactive effects of maternal health, parenting hassles, social support, and parenting stress among low-income, ethnically diverse mothers of children with behavior problems. Overall, study findings revealed few differences in regard to ethnicity/race. We found that Latina mother's experienced the highest rate of mental health problems, while black mothers experienced the lowest levels of parenting stress. It is also important to note that a significant percentage of mothers in our sample reported poor physical and mental health.

While results did not differ by race in this sample of lowincome ethnic minority mothers, findings revealed that parenting hassles were a key factor associated with parenting stress. We also found that social support buffered the relationship between parenting hassles and stress, while health status exacerbated the relationship. These findings are in line with Belsky's [7] ecological model of parenting, which posits that lower levels of personal resources and social support lead to lower levels of parent functioning. Thus, structural disadvantages may be a better predictor of parental functioning and well-being than race and ethnicity in low-income mothers of children with conduct disorders.

Study findings provide important implications for improving parent, child, and family functioning in low-income, ethnically diverse families with behavior-problem children. One key implication is the importance of screening for daily hassles in childrearing among mothers in these families. Results suggest that these mothers may be at risk for high levels of parenting stress if they experience high levels of daily childrearing hassles. In addition, mothers with poor health may be at increased risk of experiencing parenting hassles and as a result, increased parenting stress.

In addition, results from this study indicate that there may be structural inequalities among low-income mothers in their access to adequate health care that may be contributing to their personal health and ability to parent. High levels of fatigue and low levels of emotional support are often associated with poor maternal health and may present additional obstacles for mothers in performing day-to-day parenting responsibilities $[9,17,18]$. Thus, it would be critical that family practitioners provide parenting resources and social support to low-income ethnically diverse mothers of children with conduct problems who struggle with perceived daily childrearing hassles and either poor physical or mental health conditions.

As with any study, this study has notable limitations. Due to the cross-sectional nature of this study, we were limited in our ability to infer causality in the associations among maternal health status, parenting hassles, and parenting stress. The possibility of collider stratification bias may also be a concern in this study due to the division of participants by health status, and the potential that both stress and hassles may influence physical and mental health in mothers. In addition, the study was restricted to a low-income, ethnic-minority sample of mothers and kindergartners' with a high prevalence of behavior problems; families were selected if teachers reported children as being in the top quartile on the TOCA-R [29] for child behavior problems. Hence, findings may not be representative of all mothers and children. Furthermore, the use of self-report measures has intrinsic limitations. Future research may consider a longitudinal study design that includes other measures, such as observations or clinical assessments. Lastly, this study was not able to examine the influence of comorbid health conditions among mothers due to the nature and size of the sample. Examining the effect of comorbidity on parenting stress among low-income mothers who are raising children with conduct disorders would address an important gap in the literature.

In conclusion, findings in this study may inform family health professionals who work with low-income, ethnically diverse mothers and children with conduct disorders. Given the potential negative effects of parenting stress, family practitioners may consider screening these mothers for perceived daily childrearing hassles in conjunction with health issues, and providing these families with information on available health and social programs for marginalized families in the community, such as programs that offer resources for social support stress reduction, parenting and child development. The importance of screening or assessing for daily parenting stress and hassles involved in childrearing seems to be the key implication.

Acknowledgments This research was supported by the Pennsylvania Department of Health and Award Number T32 DA017629 from the National Institute on Drug Abuse. The content is solely the responsibility of the authors and does necessarily represent the official views of the Pennsylvania Department of Health or the National Institute on Drug Abuse or the National Institutes of Health. This work was also supported by NSF IGERT Big Data Social Science Award (\#DGE-1144860) and the Population Research Institute at Penn State University, Eunice Kennedy Shriver National Institute of Child Health and Human Development infrastructure grant (\#R24-HD041025).

\section{Compliance with Ethical Standards}

Conflict of Interest BeLue R, Halgunseth L, Abiero B, and Bediako P. declare that they have no conflict of interest. The content is solely the responsibility of the authors and does necessarily represent the official views of the Pennsylvania Department of Health or the National Institute on Drug Abuse or the National Institutes of Health.

Research Involving Human Subjects or Animals All procedures performed in studies involving human participants were in accordance with the ethical standards of the institutional and/or national research committee and with the 1964 Helsinki declaration and its later amendments or comparable ethical standards. This article does not contain any studies with animals performed by any of the authors.

Informed Consent Informed consent was obtained from all individual participants included in the study." 


\section{References}

1. Abidin RR. Parenting stress index. 3rd ed. Psychological Assessment Resources, Incorporated; 1995.

2. Mulsow M, Caldera YM, Pursley M, Reifman A, Huston AC. Multilevel factors influencing maternal stress during the first three years. J Marriage Fam. 2002;64:944-56.

3. DuPaul GJ, McGoey KE, Eckert TL, Vanbrakle J. Preschool children with attention-deficit/hyperactivity disorder: impairments in behavioral, social, and school functioning. J Am Acad Child Adolesc Psychiatry. 2001;40:508-15.

4. Nomaguchi KM, Brown SL. Parental strains and rewards among mothers: the role of education. J Marriage Fam. 2011;73:621-36.

5. Nomaguchi K, House AN. Racial-ethnic disparities in maternal parenting stress the role of structural disadvantages and parenting values. J Health Soc Behav. 2013;54:386-404.

6. Emmen, Rosanneke, Malda M, Mesman J, van IJzendoorn MH, L $\mathrm{J}$, Yeniad N. Socioeconomic status and parenting in ethnic minority families: testing a minority family stress model. J Fam Psychol. 2013;27:896-90.

7. Belsky J. The determinants of parenting: a process model. Child Dev. 1984;55:83-96.

8. Deater-Deckard KD. Parenting stress. Yale University Press; 2004.

9. Mistry R, Stevens GD, Sareen H, De Vogli R, Halfon N. Parentingrelated stressors and self-reported mental health of mothers with young children. Am J Public Health. 2007;97:1261-8.

10. Silver EJ, Heneghan AM, Bauman LJ, Stein REK. The relationship of depressive symptoms to parenting competence and social support in inner-city mothers of young children. Matern Child Health J. 2006;10:105-12.

11. Ardoino GI, Queirolo EI, Barg G, Ciccariello DA, Kordas K. The relationship among depression, parenting stress, and partner support in low-income women from Montevideo, Uruguay. Health Care Women Int. [Internet]. 2013 [cited 2014 Sep 24];0. Available from: doi:10.1080/07399332.2013.852552.

12. Huang CY, Costeines J, Kaufman JS, Ayala C. Parenting stress, social support, and depression for ethnic minority adolescent mothers: impact on child development. J Child Fam Stud. 2014;23:255-62

13. Ievers-Landis CE, Storfer-Isser A, Rosen C, Johnson NL, Redline S. Relationship of sleep parameters, child psychological functioning, and parenting stress to obesity status among preadolescent children. J Dev Behav Pediatr. 2008;29:243-52.

14. Park H, Walton-Moss B. Parenting style, parenting stress, and children s health-related behaviors. J Dev Behav Pediatr. 2012;33:495503.

15. Creasey G, Reese M. Mothers' and fathers' perceptions of parenting hassles: associations with psychological symptoms, nonparenting hassles, and child behavior problems. J Appl Dev Psychol. 1996;17:393-406.

16. Mensah FK, Kiernan KE. Maternal general health and children's cognitive development and behaviour in the early years: findings from the Millennium Cohort Study. Child Care Health Dev. 2011;37:44-54.

17. White CP, White MB, Fox MA. Maternal fatigue and its relationship to the caregiving environment. Fam Syst Health. 2009;27:32545.

18. Poole JL, Willer K, Mendelson C. Occupation of motherhood: challenges for mothers with scleroderma. Am J Occup Ther Off Publ Am Occup Ther Assoc. 2009;63:214-9.

19. Webster-Stratton C, Hammond M. Maternal depression and its relationship to life stress, perceptions of child behavior problems, parenting behaviors, and child conduct problems. J Abnorm Child Psychol. 1988;16:299-315.

20. Cicchetti D, Rogosch FA, Toth SL. Maternal depressive disorder and contextual risk: contributions to the development of attachment insecurity and behavior problems in toddlerhood. Dev Psychopathol. 1998;null:283-300.

21. Heflin CM, Siefert K, Williams DR. Food insufficiency and women's mental health: findings from a 3-year panel of welfare recipients. Soc Sci Med. 2005;61:1971-82.

22. Siefert K, Heflin CM, Corcoran ME, Williams DR. Food insufficiency and the physical and mental health of low-income women. Women Health. 2001;32:159-77.

23. Williams DR, Yu Y, Jackson JS, Anderson NB. Racial differences in physical and mental health socio-economic status, stress and discrimination. J Health Psychol. 1997;2:335-51.

24. Crnic KA, Greenberg MT. Minor parenting stresses with young children. Child Dev. 1990;61:1628-37.

25. Deater-Deckard K, Dodge KA, Bates JE, Pettit GS. Physical discipline among African American and European American mothers: links to children's externalizing behaviors. Dev Psychol. 1996;32: 1065-72.

26. Kam C-M, Greenberg MT, Walls CT. Examining the role of implementation quality in school-based prevention using the PATHS curriculum. Prev Sci. 2003;4:55-63.

27. Tofighi D, MacKinnon DP. RMediation: an R package for mediation analysis confidence interval. Behav Res Methods. 2011;43: 692-700.

28. Werthamer-Larsson L, Kellam S, Wheeler L. Effect of first-grade classroom environment on shy behavior, aggressive behavior, and concentration problems. Am J Community Psychol. 1991;19:585602 .

29. Radloff LS. The CES-D scale: a self-report depression scale for research in the general population. Appl Psychol Meas. 1977;1: 385-401. 